\title{
Nanometer scale spectroscopic visualization of catalytic sites during a hydrogenation reaction on a $\mathrm{Pd} / \mathrm{Au}$ bimetallic catalyst
}

Hao Yin ${ }^{1,2}$, Li-Qing Zheng ${ }^{1 *}$, Wei Fang ${ }^{1}$, Yin-Hung Lai ${ }^{1}$, Nikolaus Porenta ${ }^{1}$, Guillaume Goubert ${ }^{1}$, Hua Zhang ${ }^{2}$, Hai-Sheng $\mathrm{Su}^{2}$, Bin Ren ${ }^{2}$, Jeremy O. Richardson ${ }^{1 *}$, Jian-Feng $\mathrm{Li}^{2 *}$ and Renato Zenobi ${ }^{1 *}$

1. Department of Chemistry and Applied Biosciences, ETH Zurich, Vladimir-Prelog-Weg 3, Zurich $\mathrm{CH} 8093$, Switzerland

2. State Key Laboratory of Physical Chemistry of Solid Surfaces, Collaborative Innovation Center of Chemistry for Energy Materials (iChEM), College of Chemistry and Chemical Engineering, College of Energy, College of Materials, Xiamen University, Xiamen 361005, China

*E-mail: liqing.zheng@org.chem.ethz.ch; rjeremy@ethz.ch; li@xmu.edu.cn; zenobi@org.chem.ethz.ch 


\begin{abstract}
Understanding the mechanism of catalytic hydrogenation at the local environment requires chemical and topographic information involving catalytic sites, active hydrogen species and their spatial distribution. Here, tip-enhanced Raman spectroscopy (TERS) was employed to study the catalytic hydrogenation of chloro-nitrobenzenethiol on a welldefined $\mathrm{Pd}\left(\right.$ sub-monolayer)/Au(111) bimetallic catalyst $\left(p_{\mathrm{H} 2}=1.5\right.$ bar, $\left.298 \mathrm{~K}\right)$, where the surface topography and chemical fingerprint information were simultaneously mapped with nanoscale resolution $(\approx 10 \mathrm{~nm})$. TERS imaging of the surface after catalytic hydrogenation confirms that the reaction occurs beyond the location of Pd sites. The results demonstrate that hydrogen spillover accelerates hydrogenation at the Au sites within $20 \mathrm{~nm}$ from the bimetallic Pd/Au boundary. Density functional theory was used to elucidate the thermodynamics of interfacial hydrogen transfers. We demonstrate that TERS as a powerful analytical tool provides a unique approach to spatially investigate the local structure-reactivity relationship in catalysis.
\end{abstract}




\section{Introduction}

Spatially resolved investigation of surface active sites with molecular specificity contributes to revealing structure-reactivity relationships in catalytic processes ${ }^{1,2}$. For example, the spatial distribution of atomic hydrogen in selective hydrogenation has been reported to strongly affect the local selectivity and conversion rate, especially for multi-metallic catalysts ${ }^{3,4}$. One important factor which contributes to this effect is hydrogen spillover, in which atomic hydrogen can migrate from sites on metals that catalyze $\mathrm{H}_{2}$ dissociation to the surrounding support (other metals ${ }^{5,6}$, oxides ${ }^{7}$, carbon $^{8}$ ). Many methods have been developed to study hydrogen spillover, such as scanning tunneling microscopy $(\mathrm{STM})^{9}$, temperature-programmed desorption (TPD) ${ }^{10}$, in-situ Xray absorption spectroscopy (XAS) $)^{11}$, and low energy electron diffraction (LEED) ${ }^{12}$.

Catalytic hydrogenation and hydrogen migration mostly occur at specific sites of a catalyst, often associated with defects of surface heterogeneity ${ }^{1}$, thus it is necessary to develop a method for observing hydrogen spillover at the nanoscale in order to identify these active sites. However, only few methods ${ }^{9,11}$ can achieve nanoscale resolution, and generally only under ultra-high vacuum (UHV), which is far from the actual reaction conditions. It is thus still a challenge to spectroscopically visualize catalytic sites and hydrogen spillover regions with nanoscale spatial resolution at temperatures and pressures approaching those relevant for mild catalytic conditions.

Tip-enhanced Raman spectroscopy (TERS) combines enhanced Raman spectroscopy ${ }^{13}$ with scanning probe microscopy and provides chemical fingerprint and topographic information simultaneously. As a typical near-field optical method, TERS can achieve high spatial resolution down to $3 \mathrm{~nm}$ at ambient conditions ${ }^{14}$ and even submolecular resolution under cryogenic conditions in $U \mathrm{HV}^{15}, 16$. It is an ideal tool for monitoring catalytic reactions on surfaces. For example, Deckert, Weckhuysen and coworkers ${ }^{17}$ used TERS to study a plasmon-induced photocatalytic reaction in a single spot. Ren and coworkers ${ }^{14}$ used a TERS line scan to reveal the relationship between surface electronic properties and catalytic activity. This motivated us to employ TERS imaging, which provides more comprehensive information about the surface, to identify 
the spatial distribution of active sites and reactive species on a catalyst surface, even though it is more challenging.

Here, we combine ambient STM-TERS and density functional theory (DFT) to study the selective hydrogenation of chloro-nitrobenzenethiol (CNBT) to chloroaminobenzenethiol (CABT) on an atomically flat and well-defined bimetallic $\mathrm{Pd} / \mathrm{Au}(111)$ catalyst with $\sim 10 \mathrm{~nm}$ spatial resolution, in order to discern the structure-reactivity relationship and to determine the extent of hydrogen spillover. TERS line scans and TERS maps confirmed that the reactive regions for hydrogenation are not only located on the $\mathrm{Pd}$ regions, but extend by $\sim 20 \mathrm{~nm}$ into Au regions as a result of hydrogen spillover. This constitutes direct spectroscopic evidence of hydrogen spillover on a bimetallic interface.

\section{Results}

\section{Model catalytic reaction}

Atomically flat and well-defined bimetallic catalysts with various kinds of $\mathrm{Pd} / \mathrm{Au}$ interfaces allow investigation of the structure-activity relationship at different sites. The selective hydrogenation of chloro-nitrobenzenethiol on $\mathrm{Pd}$ and $\mathrm{Au}$ individually, together with the schematic of TERS using a Ag tip to probe the hydrogenation products on a $\mathrm{Pd} / \mathrm{Au}$ bimetallic substrate are shown in Fig. 1a,b. In this work, a (sub)monolayer of $\mathrm{Pd}$ was deposited on a Au (111) surface using underpotential deposition (UPD) (Fig. 1c), a widely accepted electrochemical approach to prepare well-defined bimetallic substrates $^{14,18}$. Different coverages of Pd deposition on $\mathrm{Au}$ (111) were obtained by controlling the applied potential, as illustrated in Figure 1d-f. The STM image of a bare $\mathrm{Au}$ (111) substrate shows atomically flat terraces ca. $600 \mathrm{~nm}$ wide, and only very few atomic steps (Fig. 1d). At low $\mathrm{Pd}$ coverage ( $\mathrm{Pd}_{\mathrm{LC}} / \mathrm{Au}$, Fig. 1e), a number of $\mathrm{Pd}$ islands with a size of ca. $20 \mathrm{~nm}$ are visible on the $\mathrm{Au}$ (111) terraces, whereas at high $\mathrm{Pd}$ coverage $\left(\mathrm{Pd}_{\mathrm{HC}} / \mathrm{Au}\right.$, Fig. 1f), Au craters are visible in the Pd layer on the terraces and step edges. The chemical state of $\mathrm{Pd}$ in the deposited layer remained metallic, as confirmed by X-ray photoelectron spectroscopy (XPS) (Supplementary Figure 1). 


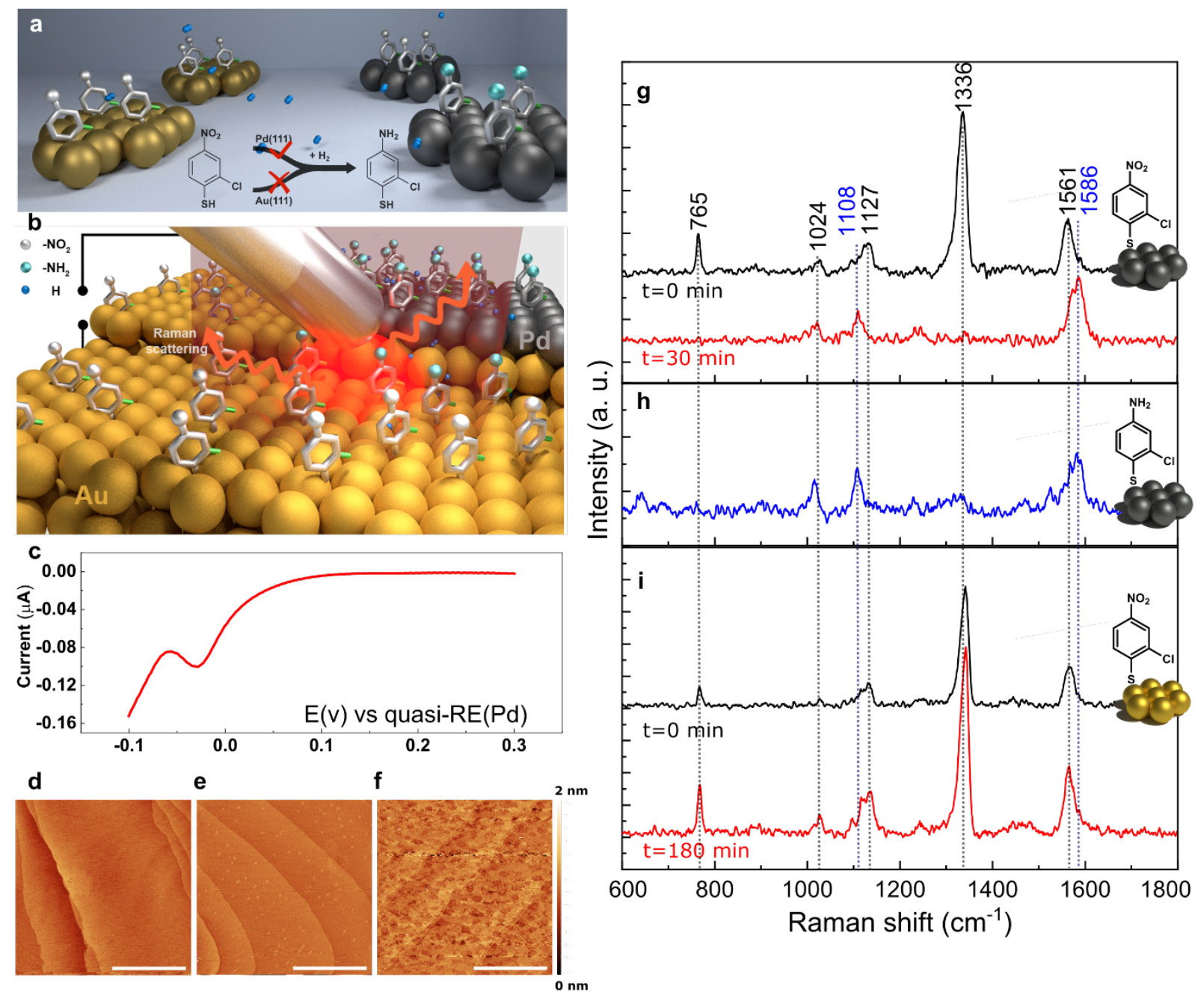

Figure 1. TERS studies of monometallic and bimetallic model catalysts. a. Schematic of the selective catalytic hydrogenation of CNBT. b. Schematic of STM-TERS using a Ag tip to probe the hydrogenation products on a $\mathrm{Pd} / \mathrm{Au}$ bimetallic substrate. c. Linear sweep voltammetry curve showing the underpotential deposition peak of $\mathrm{Pd}$ at $-0.025 \mathrm{~V}$ on a $\mathrm{Au}(111)$ surface. d-f. STM images of pure $\mathrm{Au}(111)$ (d), $\mathrm{Pd}$ on $\mathrm{Au}(111)$ at a low $\mathrm{Pd}$ coverage $\left(\mathrm{e}, \mathrm{Pd}_{\mathrm{LC}} / \mathrm{Au}\right)$ and at a high coverage $\left(\mathrm{f}, \mathrm{Pd}_{\mathrm{HC}} / \mathrm{Au}\right)$. All STM images have dimensions of 1,000 nm $\times 1,000 \mathrm{~nm}$ and were obtained using Ag tips (scale bar, $400 \mathrm{~nm}$ ). $\mathrm{g}$ i. TER spectra of CNBT on $\mathrm{Pd}(\mathrm{g})$ and $\mathrm{Au}$ (i), before (black trace) and after (red trace) exposure to $\mathrm{H}_{2}$, and TER spectra of CATP on Pd as reference (h, blue trace).

The selective hydrogenation of chloro-nitrobenzene to chloro-aniline is widely applied in the industrial production of fine chemicals ${ }^{4,19}$. A thiol group was attached to chloronitrobenzene, because the strong covalent interaction between the metal surface and 
thiols efficiently immobilized the molecules on the surface. CNBT was used as a Raman probe to investigate the catalytic properties of bimetallic surfaces. During exposure to a $\mathrm{H}_{2}$ atmosphere, molecular hydrogen first chemisorbs onto the $\mathrm{Pd}$ surface and is then dissociated into hydrogen atoms, which leads to the hydrogenation of CNBT. This reaction hardly occurs on a $\mathrm{Au}(111)$ surface, due to the high energy barrier for $\mathrm{H}_{2}$ dissociation on Au under our reaction conditions ${ }^{3,4}$. After the sample was exposed to $\mathrm{H}_{2}$ for $1.5 \mathrm{~h}$, we utlized STM-TERS to characterize the surface products as described in Figure 1b. By using a low excitation laser power $(70 \mu \mathrm{W})$, we also avoided any photocatalytic reaction in our system during TERS measurements (Figure 1g-i and Supplementary Figure 2).

Before investigating the hydrogenation on the bimetallic model catalyst, we performed control experiments on pure Au and Pd. Tip-enhanced Raman spectra of CNBT (black line, Fig. $1 \mathrm{~g}$ and $1 \mathrm{i}$ ) on $\mathrm{Pd}$ and $\mathrm{Au}$ before the hydrogenation are similar, which indicates that the orientation of CNBT molecules adsorbed on $\mathrm{Au}$ and $\mathrm{Pd}$ is similar. After exposure to 1.5 bar of $\mathrm{H}_{2}$ for $3 \mathrm{~h}$, the TER spectral features of CNBT on Au remain the same (Fig. 1i). When we prolong the reaction time to $27 \mathrm{~h}$, CNBT molecules remain unreacted on the Au surface (Supplementary Figure 2) because the Au surface is not able to catalyze the hydrogen dissociation under current reaction conditions ${ }^{20}$. On the contrary, distinct changes were observed in the TER spectrum of the CNBT monolayer on the $\mathrm{Pd}$ surface after exposure to $\mathrm{H}_{2}$ (Fig. $1 \mathrm{~g}$ ): the peaks at $1,336 \mathrm{~cm}^{-1}\left(\mathrm{NO}_{2}\right.$ stretching) and $765 \mathrm{~cm}^{-1}(\mathrm{C}-\mathrm{Cl}$ stretching of $\mathrm{CNBT})$ disappear, while the $\mathrm{C}=\mathrm{C}$ stretching band shifts from $1,567 \mathrm{~cm}^{-1}$ to $1,586 \mathrm{~cm}^{-1}$ and the C-S stretching shifts from $1,127 \mathrm{~cm}^{-1}$ to $1,108 \mathrm{~cm}^{-1}$ (Supplementary Figure 3 , Table 1). All these spectral features match the TER spectrum of CABT (Figure $1 \mathrm{~h}$ ) as well as the simulated and confocal Raman spectra (Supplementary Figure 4), but differ from the TER spectrum of 4aminothiophenol (ATP) (Supplementary Figure 5), which indicates that CNBT was selectively reduced to CABT by the Pd catalyst. Using in situ time-series surfaceenhanced Raman spectroscopy (SERS) (Supplementary Figure 6) and temperatureprogrammed desorption mass spectroscopy (TPD-MS) (Supplementary Figure 7), we were further able to prove that hydrogenation to CABT only occurs on the Pd surface with high selectivity, but not on Au. We also measured the hydrogenation of $\mathrm{p}$ - 
nitrobenzenethiol (pNTP) without the $\mathrm{Cl}$ group on $\mathrm{Pd}$ and $\mathrm{Au}$, respectively (Supplementary Figure 8). Catalysed by Pd, the pNTP molecules were converted to ATP, indicating that the selectivity of the reduction does not depend on the chlorine substituent.

\section{Spectroscopic identification of active sites at the nanoscale}

Hydrogenation of CNBT self-assembled monolayers (SAMs) on $\mathrm{Pd} / \mathrm{Au}$ bimetallic surfaces was then studied by exposing the CNBT@PdLC/Au and CNBT@Pd $d_{H C} / A u$ samples to 1.5 bar of $\mathrm{H}_{2}$ for $1.5 \mathrm{~h}$ at room temperature. For $P d_{L C} / A u$, the STM image shows several monoatomic palladium islands on the $A u(111)$ surface (Supplementary Fig. 9a). For $\mathrm{Pd}_{\mathrm{HC}} / \mathrm{Au}$, the STM image shows that the $\mathrm{Pd}$ has merged into a (sub)monolayer with remaining Au craters on the surface (Supplementary Fig. 9b). To obtain local information after exposure to $\mathrm{H}_{2}$ molecules, we acquired $300 \times 300 \mathrm{~nm}^{2}$ TERS maps with a $10 \mathrm{~nm}$ step size. From each TERS map, we extracted TER spectra along a line that runs across a grain boundary. An overlay of the TER spectra and the corresponding STM images is shown in Figure 2. The STM data showing the surface topography along with schematic diagrams of two typical samples are displayed: three 20 nm-size $\mathrm{Pd}$ islands and a $\mathrm{Au} / \mathrm{Au}$ step edge for $\mathrm{Pd} \mathrm{d}_{\mathrm{LC}} / \mathrm{Au}$ (Fig. 2a), two Au craters and a $\mathrm{Pd} / \mathrm{Pd}$ step edge for $\mathrm{Pd}_{\mathrm{HC}} / \mathrm{Au}$ (Fig. 2d). As the plasmonic tip was scanned over the bimetallic substrate molecular vibrational signals were collected.

We were able to distinguish CNBT from CATP to determine the reactive sites, based on the presence or absence of the $\mathrm{NO}_{2}$ mode at $1336 \mathrm{~cm}^{-1}$ and on the shifts of the $\mathrm{C}=\mathrm{C}$ vibration frequency, as described in Fig. 1d. In some of the spectra in Figures $2 \mathrm{c}$ and $2 \mathrm{f}$ (purple traces), the $v\left(\mathrm{NO}_{2}\right)$ peak at $1,336 \mathrm{~cm}^{-1}$ disappeared and the $\mathrm{C}=\mathrm{C}$ stretching frequency shifted to $1,586 \mathrm{~cm}^{-1}$, indicating the formation of CABT at these sites. Interestingly, the spatial distribution of these spectra showed a clear correlation with the locations of the $\mathrm{Pd}$ islands. For $\mathrm{Pd}_{\mathrm{LC}} / \mathrm{Au}$, the band at $1,336 \mathrm{~cm}^{-1}$ only disappeared the $\mathrm{Pd}$ islands, but remained in the $\mathrm{Au}$ areas (Fig. 2c). For $\mathrm{Pd}_{\mathrm{HC}} / \mathrm{Au}$, the band at $1,336 \mathrm{~cm}^{-1}$ disappeared in most of the spectra and was only visible in the top five spectra of the line scan (Fig. 2f, pink traces, zoomed-in image of the TER spectra is shown in Supplementary Figure 10), while the peak at around $1,586 \mathrm{~cm}^{-1}$ broadened and shifted 
to lower wavenumbers, corresponding to the large, inactive Au crater (Fig. $2 d$ and $2 e$, $\mathrm{Au} \# 1$ ). We did not observe the reduction of CNBT at Au grain edges or terraces (Supplementary Figure 11). Remarkably, the band at $1,336 \mathrm{~cm}^{-1}$ was not present in the spectra acquired in the small Au crater (Fig. $2 d$ and 2e, Au \#2). We interpret this as a sign of hydrogen spillover from the Pd area to the small Au crater. However, hydrogen spillover was not effective to cover the whole Au area if the Au crater was larger than 50 $\mathrm{nm}$. Additional evidence was the frequency shift of the ring stretching mode in the TER spectra acquired across the boundary of Pd/Au areas (Supplementary Figure 12, Table 2). The data thus confirms that most of the reactive sites are located on Pd.
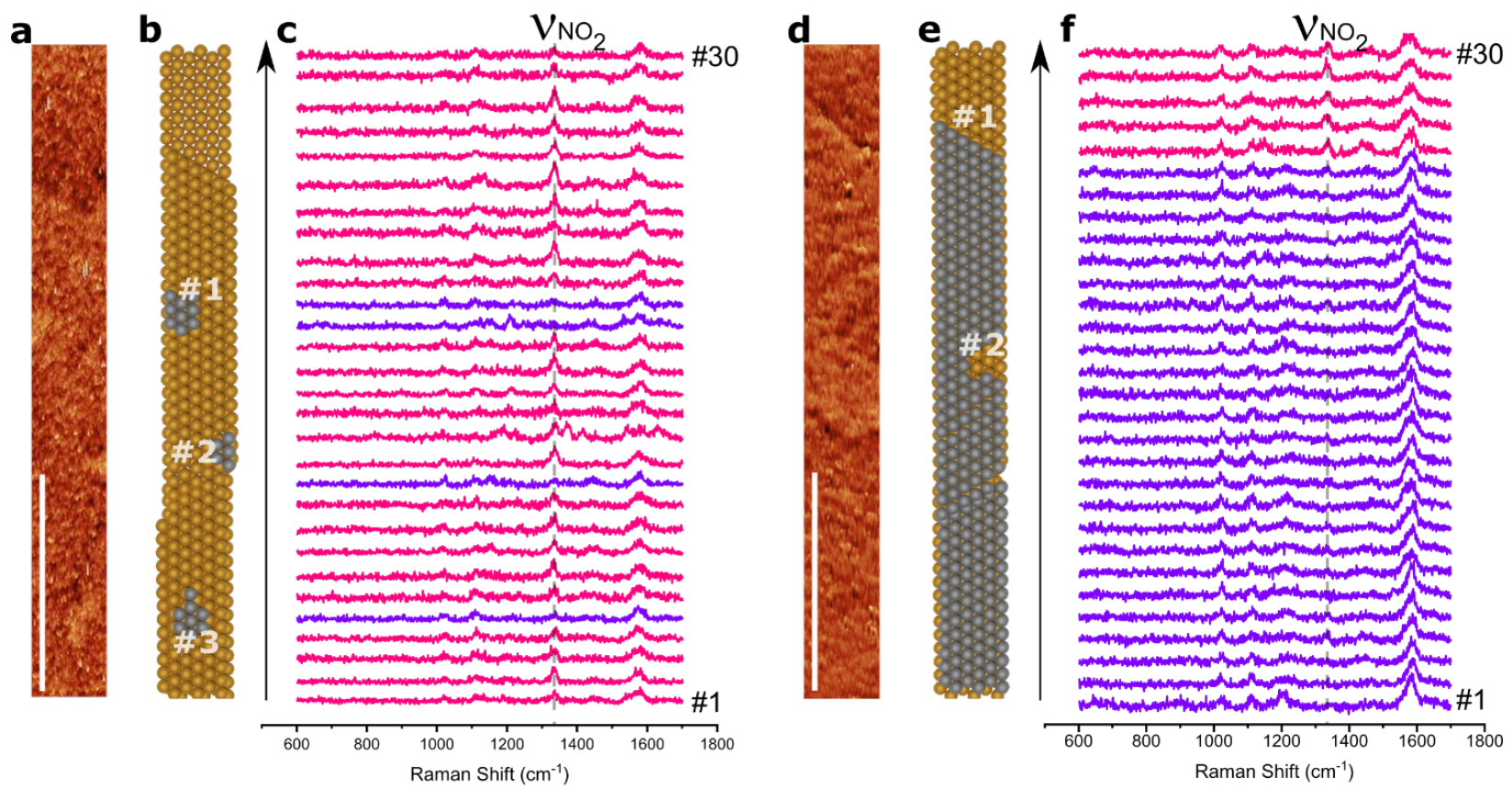

Figure 2. TERS line scan results. a, d. STM images of CNBT SAMs on $P d_{L C} / A u$ (a) and $P d_{H C} / A u$ (d) (scale bar, $100 \mathrm{~nm}$ ). b, e. Schematic illustration of the atomic structure of the surfaces shown in the STM images with Pd colored grey and Au colored gold (not to scale). c, f. TER spectra extracted from the TERS maps of CNBT SAMs on $\mathrm{Pd}_{\mathrm{LC} / \mathrm{Au}}$ (c) and on $\mathrm{Pd}_{\mathrm{HC}} / \mathrm{Au}$ (f) after exposure to $\mathrm{H}_{2}$ for $1.5 \mathrm{~h}$, acquired along the regions indicated in the STM images with every $10 \mathrm{~nm}$ per spectrum. 

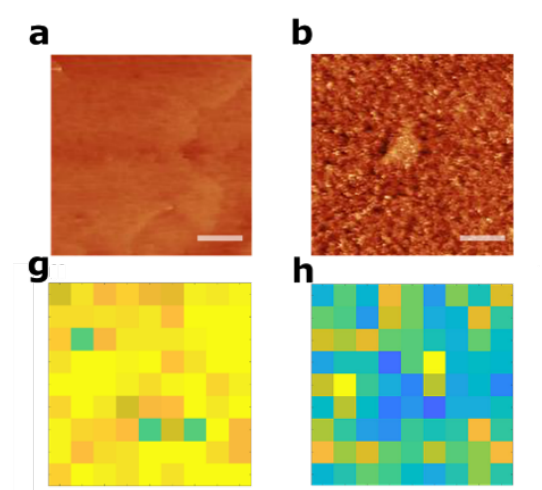

m
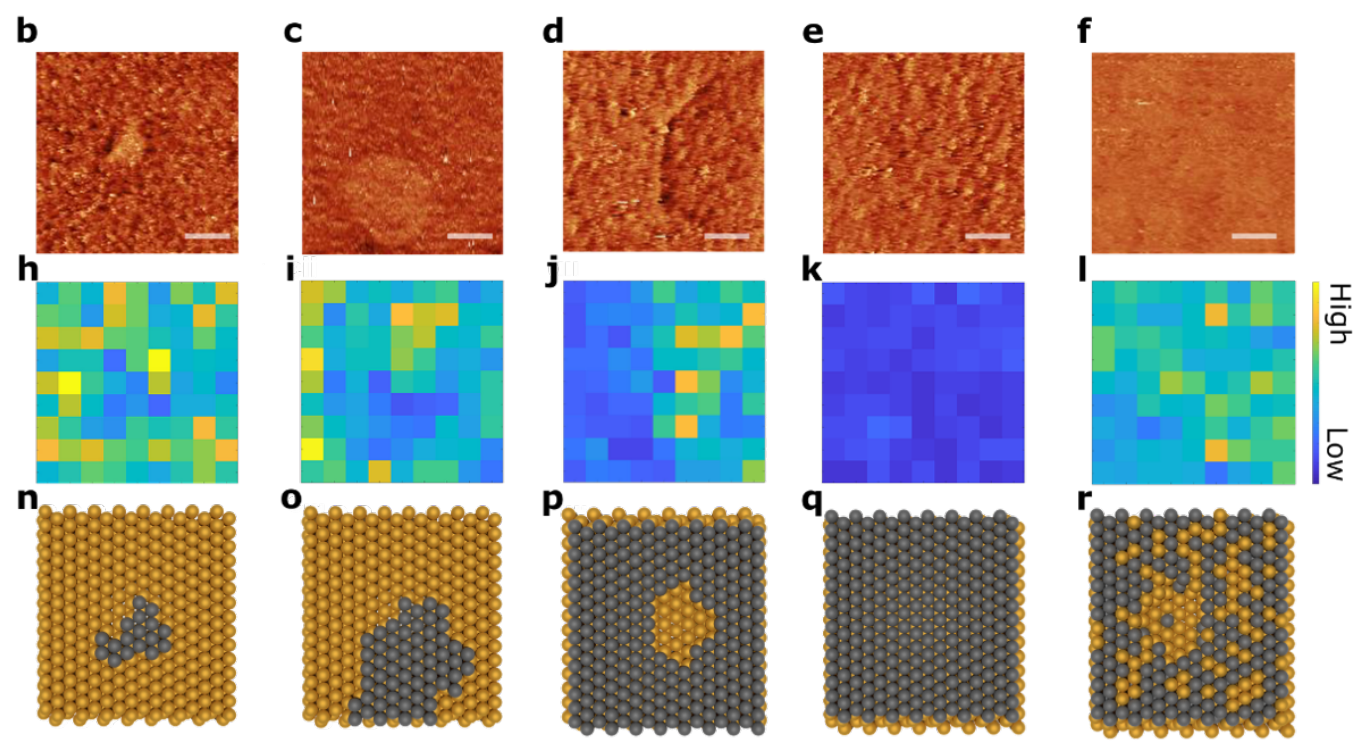

Figure 3. TERS 2D maps. a-f. STM images of $A u(111)$, bimetallic substrates with increasing Pd coverage, and a Pd/Au alloyed substrate. Scale bars: a. $40 \mathrm{~nm}$, b-f. $20 \mathrm{~nm}$. g-l. Peak intensity maps of the $1336 \mathrm{~cm}^{-1}$ TERS signal of the CNBT SAM, after exposure to $\mathrm{H}_{2}$ (normalized to the peak of the $\mathrm{C}=\mathrm{C}$ stretching mode) at the same region as that of the STM images. m-r. Atomic models illustrating the $\mathrm{Pd} / \mathrm{Au}$ surfaces (not to scale).

The co-localized STM images and TERS line scans provide comprehensive information which reveal that $\mathrm{Pd}$ can catalyze the selective hydrogenation of CNBT, while Au cannot. However, the spatial information provided is limited to one dimension. For a more powerful analysis, we expanded the analyzed region to a two-dimensional, $90 \times 90 \mathrm{~nm}^{2}$ area. TERS maps of the peak at $1,336 \mathrm{~cm}^{-1}$ (normalized to the peak of the $\mathrm{C}=\mathrm{C}$ stretching mode) of CNBT SAMs after exposure to $\mathrm{H}_{2}$ for $1.5 \mathrm{~h}$ and the colocalized STM images are shown in Figure 3 and Figure 4 (Fig. 4a-d, $\mathrm{Pd}_{\mathrm{HC}} / \mathrm{Au}$ and Fig. $4 \mathrm{e}-\mathrm{h}, \mathrm{Pd} \mathrm{LC} / \mathrm{Au}$ ). We measured the hydrogenation rate on $\mathrm{Au}(111)$ (Figure $3 \mathrm{a}, 3 \mathrm{~g}$, and $3 \mathrm{~m})$ and on bimetallic catalysts with different $\mathrm{Pd}$ coverages, including low coverage $\left(P d_{L C} / A u(111)\right.$; Figure $3 b, 3 h$, and $\left.3 n\right)$, medium coverage ( $P d_{M C} / A u(111)$; Figure 3c, 3i, and 3o), high coverage $\left(\mathrm{Pd}_{\mathrm{HC}} / \mathrm{Au}(111)\right.$; Figure $3 \mathrm{~d}, 3 \mathrm{j}$, and $\left.3 p\right)$, full coverage $\left(\mathrm{Pd}_{\mathrm{FC}} / \mathrm{Au}(111)\right.$; Figure $3 \mathrm{e}, 3 \mathrm{k}$, and $\left.3 \mathrm{q}\right)$, and on a $\mathrm{Pd} \mathrm{f}_{\mathrm{FC}} / \mathrm{Au}(111)$ alloy (Figure $3 \mathrm{f}, 3 \mathrm{l}$, and $3 r)$. The distribution of the peak intensity of $\mathrm{NO}_{2}$ vibrations $\left(1336 \mathrm{~cm}^{-1}\right)$ within these maps clearly shows a negative correlation with $\mathrm{Pd}$ coverage, indicating that $\mathrm{Pd}$ 
possesses higher hydrogenation efficiency than $\mathrm{Au}$. It is worth to mention that alloy formation potentially changes the reactivity as the result of electronic/geometric/interfacial effects. Even though $\mathrm{Pd}$ and $\mathrm{Au}$ can relatively easily form a substitutional alloy with atom exchange, Kolb et al. ${ }^{33}$ reported that alloy formation at the metal surface played no significant role in the underpotential deposition of $\mathrm{Pd}$ on $\mathrm{Au}(111)$. To form an alloyed surface, we immersed a $\mathrm{Pd}$ on $\mathrm{Au}(111)$ substrate into a CNBT solution for more than 200 hours at room temperature before $\mathrm{H}_{2}$ treatment. The STM image and TERS map of CNBT on a Pd/Au alloyed surface after $\mathrm{H}_{2}$ treatment for $1.5 \mathrm{~h}$ were then collected and are shown in Figure $3 \mathrm{f}, 3 \mathrm{l}$, and $3 \mathrm{r}$. In the STM image, the boundary between $\mathrm{Pd}$ and $\mathrm{Au}$ is difficult to distinguish, due to the formation of $\mathrm{Pd} / \mathrm{Au}$ alloy. We surmise that there are many $\mathrm{Pd} / \mathrm{Au}$ interfaces present in this image. With more $\mathrm{Pd} / \mathrm{Au}$ interfaces (Figure $3 \mathrm{l}$ ), we observed higher reactivity than on pure $\mathrm{Au}(111)$ (Figure $3 \mathrm{~g}$ ) but lower reactivity compared to $\mathrm{Pd}_{\mathrm{FC}} / \mathrm{Au}$ (Figure $3 \mathrm{k}$ ). This indicates that the interfacial effects played no significant role in our reaction system. Moreover, there was no ATP peak $\left(\sim 1,074 \mathrm{~cm}^{-1}\right)$ observed in the TERS data, which means that the formation of $\mathrm{Pd} / \mathrm{Au}$ alloy did not affect the selectivity of the reaction.

\section{Visualization of hydrogen spillover at the Pd/Au interface}

In order to clearly demonstrate the correlation between the surface topography and the hydrogenation of the nitro group, we highlighted the contours of the Au crater (Figure 4a) and the $\mathrm{Pd}$ island (Figure $4 \mathrm{e}$ ) in the STM images and overlaid them with the corresponding TERS maps. Height profiles and the intensity of the $1,336 \mathrm{~cm}^{-1}$ TERS band were plotted for orthogonal sample cross-sections (Fig. 4, black lines). In agreement with the results from TERS line scans (Fig. 2), 2D intensity maps show that the intensity of the peak at $1,336 \mathrm{~cm}^{-1}$ is weaker on the Pd region than on the Au region (Figure $4 \mathrm{~b}$ and $4 \mathrm{f}$ ), which confirms that the $\mathrm{Pd}$ regions have higher catalytic activity. In contrast, before exposure to $\mathrm{H}_{2}$, for $\mathrm{Pd}_{\mathrm{LC}} / \mathrm{Au}$, there was no significant decrease in the intensity of the peak at $1,336 \mathrm{~cm}^{-1}$ at the Pd islands (Supplementary Figure 13). 

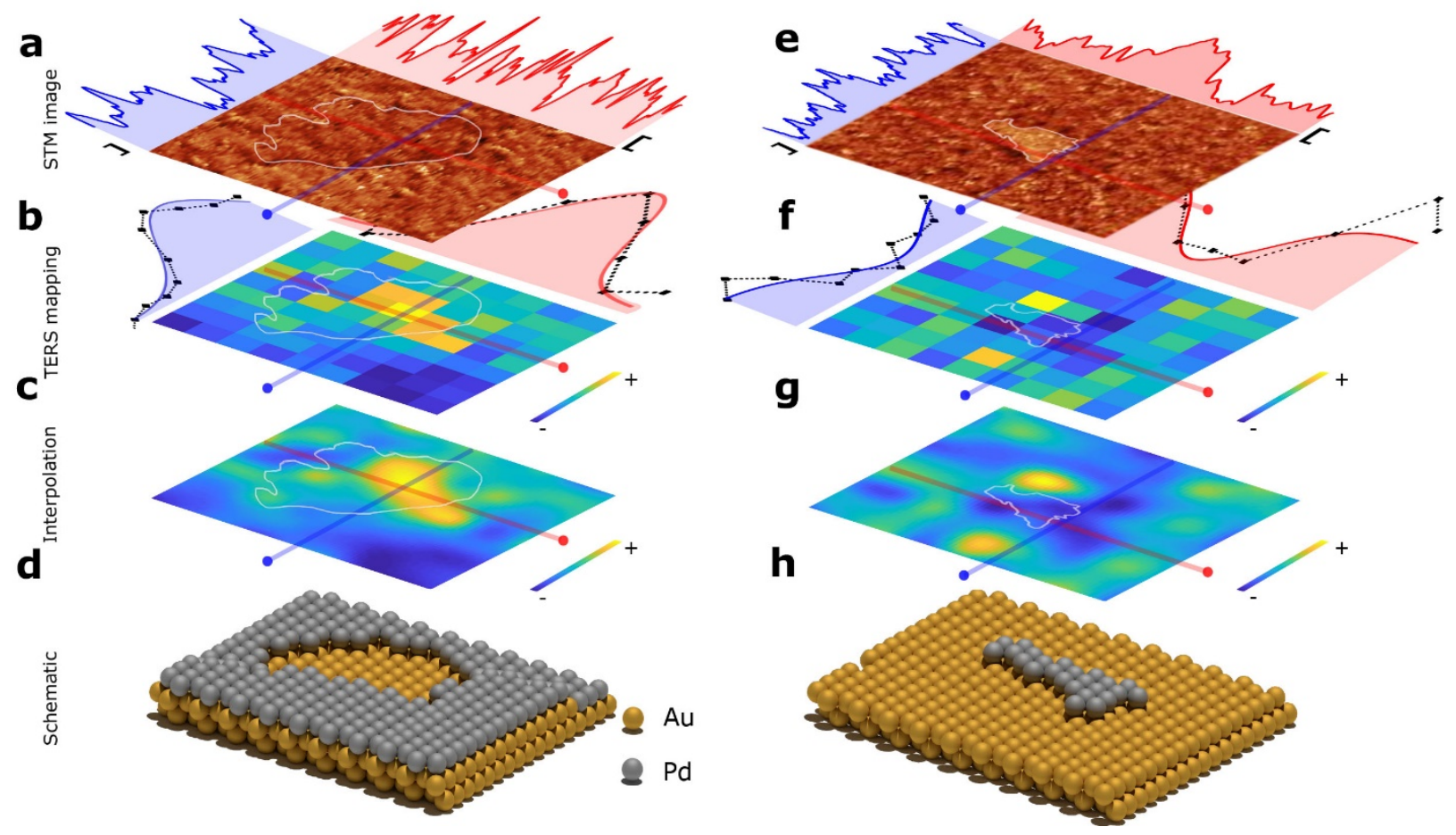

Figure 4. TERS maps revealing hydrogen spillover. a, e. STM images of CNBT SAMs on $P d_{H C} / A u(a)$ and $\mathrm{Pd}_{\mathrm{LC}} / \mathrm{Au}(\mathrm{e})$ after exposure to $\mathrm{H}_{2}$, showing a $\mathrm{Au}$ crater (d) and a $\mathrm{Pd}$ island (h) in the center, respectively. The scale bar in the STM image represents $20 \mathrm{~nm}$. The blue and pink curves are height profiles obtained along the cross-sections. The scale bar of the profile is $0.3 \mathrm{~nm}$. $\mathbf{b}$, $\mathbf{f}$. The normalized $1336 \mathrm{~cm}^{-1}$ TERS peak maps of CNBT SAMs on $\mathrm{Pd}_{\mathrm{HC}} / \mathrm{Au}$ and on $\mathrm{Pd}_{\mathrm{LC}} / \mathrm{Au}$ after exposure to $\mathrm{H}_{2}$ (normalized to the peak of the $\mathrm{C}=\mathrm{C}$ stretching mode), co-localized with the STM images. The blue and pink curves are the plots of the peak ratio obtained along the cross-sections. c, g. Cubic spline interpolation of the TERS maps shown in $\mathbf{b}$ and $\mathbf{f}$. $\mathbf{d}, \mathbf{h}$. Atomic models illustrating the Pd/Au surfaces (not to scale).

Remarkably, regardless of $\mathrm{Pd}$ coverage, there is a slight mismatch between the spatial distribution of the reactive species and the Pd areas: the size of the low-reactivity region (strong TERS intensity) is smaller than the size of the Au crater (Fig. 4a, 4b). Likewise, the size of the high-reactivity region (low TERS intensity) is larger than the size of the Pd island (Fig. 4e, 4f). The convolution effect of a TERS tip typically results in an artificial expansion of the area which shows a strong TERS signal. For example, the size of the CNTs in the TERS images is usually larger than their actual size due to the tip convolution effect ${ }^{21}$. However, the phenomena we observed here are different. For $\mathrm{Pd}_{\mathrm{HC}} / \mathrm{Au}$, the size of the low-reactivity region (strong TERS intensity) is smaller than 
the size of the Au crater. This indicates that these phenomena are not caused by the convolution effect. Another concern is the possible contribution of the surface diffusion of adsorbed thiolates. First, the cleanness of a used Ag tip was checked to confirm that no thiolate desorption occurred during the TERS measurements (Supplementary Figure 14). Additionally, we calculated that the adsorption energy difference is $1.07 \mathrm{eV}$ between $C A B T$ on $P d$ and $C A B T$ on $A u$, suggesting that the diffusion of thiolates from $\mathrm{Pd}$ to $\mathrm{Au}$ is more difficult than the $\mathrm{H}$ spillover from $\mathrm{Pd}$ to $\mathrm{Au}$. Hence we concluded that the diffusion of thiolates could be neglected in our system during both $\mathrm{H}_{2}$ treatment and TERS measurements (Supplementary Figure 14). We therefore interpret this as a sign of hydrogen spillover: after dissociation of hydrogen molecules on $\mathrm{Pd}$, adsorbed hydrogen atoms diffuse onto the adjacent $\mathrm{Au}$ surfaces (spillover) and trigger the hydrogenation there.

For a better understanding of the hydrogenation process, the relationship between the reactive region and the surface structures was quantitatively characterized. As presented in Figure 5, we show four $100 \mathrm{~nm}$-wide regions with $\mathrm{Pd}$ islands (5a, 5c) and Au craters $(5 \mathrm{e}, 5 \mathrm{~g})$ in the TERS maps, and present the co-localized STM images with height profiles $(5 b, 5 d, 5 f, 5 h)$. We applied data fitting to the peak ratio profiles $\left(v_{\mathrm{NO} 2} / v_{\mathrm{C}=\mathrm{C}}\right)$ with a full-width at half-maximum (FWHM) analysis to identify the size of the reactive region (details in Supplementary Fig. 15) ${ }^{22}$. The reactive region is indicated in light blue color and the non-reactive region is indicated in light red color. For $\mathrm{Pd}_{\mathrm{LC}} / \mathrm{Au}$ (Fig. $5 \mathrm{a}$ and $5 \mathrm{c}$ ), the size of the reactive regions defined by both fits is ca. $50 \mathrm{~nm}$ in the intensity profiles. However, the size of the Pd islands in both regions is only $20 \mathrm{~nm}$. For $\mathrm{Pd}_{\mathrm{HC}} / \mathrm{Au}$ (Fig. $5 \mathrm{e}$ and $5 \mathrm{~g}$ ), the size of the reactive regions is thus around $15 \mathrm{~nm}$ larger than the size of the Pd layer. In addition, when the hotspot is fully located on the nonreactive region, the TER intensity reaches a plateau as observed in Figure $5 \mathrm{~g}$. To minimize the convolution effect from the tip, we fitted the data with cumulative distribution function (CDF) and deconvoluted the curve in Fig. $5 \mathrm{~g}$ to identify the true size of the reactive region (Supplementary Fig. 15). Consistent with results of the 2D maps in Figure 4, the reactive regions are around 15 30 nm larger than the size of the Pd areas, indicating that the reactive regions where hydrogenation takes place, extend beyond the $\mathrm{Pd}$ areas and onto the $\mathrm{Au}$ areas. The spillover regions are not symmetric 
relative to the shape of the $\mathrm{Pd}$ islands (Figure $5 \mathrm{a}$ and $5 \mathrm{c}$ ). This may be the result of the unavoidable thermal drift over the duration of the TERS measurements at ambient conditions (Supplementary Fig. 16). The spatial resolution was estimated to be around $10 \mathrm{~nm}$ based on a FWHM analysis (Supplementary Fig. 17) ${ }^{14}$. Given all the evidence, we conclude that hydrogenation due to spillover of adsorbed $\mathrm{H}$ atoms occurs on $\mathrm{Au}$ over a distance of around 15-30 nm from the Pd catalytic sites.

a

b
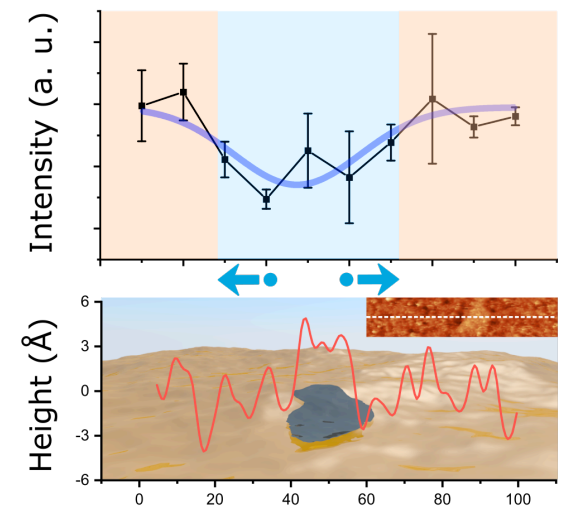

C
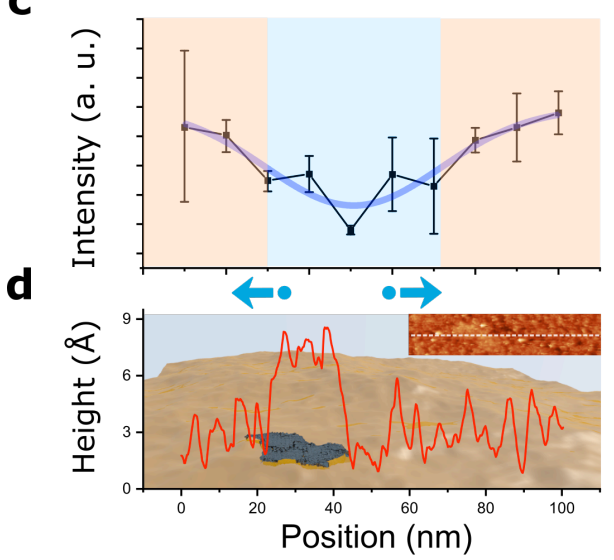

e
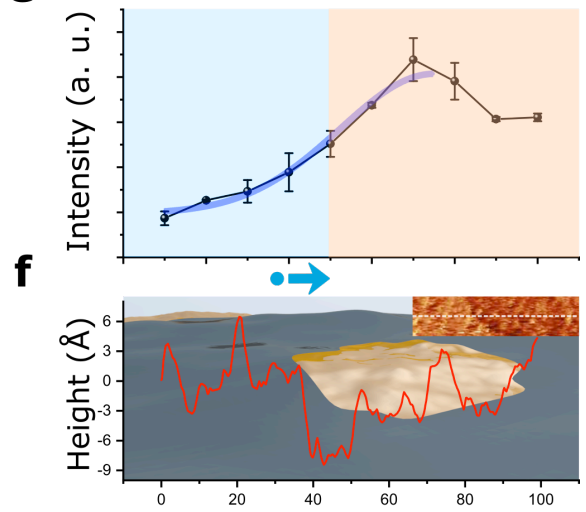

$\mathbf{g}$

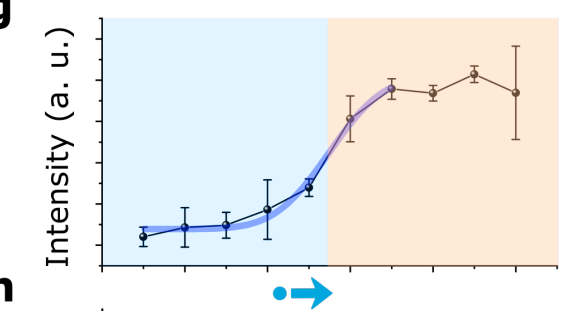

h

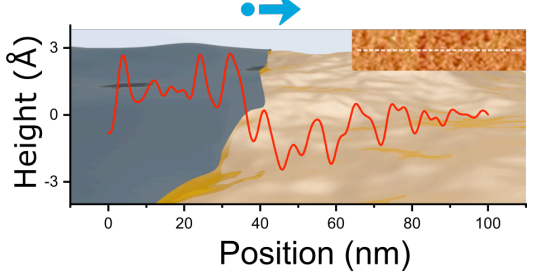

Figure 5. Hydrogen spillover region identification. a, c, e, g. Plots of the peak intensity of the $1336 \mathrm{~cm}^{-1}$ mode in four different TERS line scan spectra extracted from the TERS map of a CNBT SAM on $\mathrm{Pd}_{\mathrm{LC}} / \mathrm{Au}(\mathbf{a}, \mathbf{c})$ and $\mathrm{Pd}_{\mathrm{HC}} / \mathrm{Au}(\mathbf{e}, \mathbf{g})$ after exposure to $\mathrm{H}_{2}$. Error bars indicate standard deviation for the two adjacent TERS line scans. The blue regions in the intensity plots indicate the reactive region defined by the FWHM of the fitted curves (purple trace). $\mathbf{b}, \mathbf{d}, \mathbf{f}, \mathbf{h}$. Topographic height profile of the surface along the dashed line of the inset corresponding STM images, superimposed with the schematic of the surface structure. The yellow and gray shades represent $\mathrm{Au}$ and $\mathrm{Pd}$, respectively. The blue regions in the profile plots indicate the size of $\mathrm{Pd}$ areas. Navy blue arrows represent the hydrogen spillover regions. 


\section{Density functional theory studies}

DFT calculations were performed to further understand the mechanism of the hydrogenation of CNBT at the molecular level. Detailed discussions of the computational results are given in the supplementary information, here we summarize the key findings. Figure $6 \mathrm{a}$ shows that the adsorption of $\mathrm{H}$ atoms on $\mathrm{Au}$ is thermodynamically unfavorable, in contrast to $\mathrm{Pd}$, where it is favored, and surface atomic hydrogen hopping between $\mathrm{FCC} / \mathrm{HCP}$ sites is relatively rapid (discussed in Supplementary Fig. 21) ${ }^{23,24}$. Furthermore, we estimated the potential energy barrier for $\mathrm{H}$ atom diffusion from the $\mathrm{Pd}$ island to the $\mathrm{Au}$ substrate based on adsorption energy differences (Supplementary Eq. 2) with thiolates co-adsorbed on the surface (0.25 ML coverage) and on a clean surface. As shown in Figure 6a and Supplementary Figure 21, they are $0.84 \mathrm{eV}$ and $0.93 \mathrm{eV}$, respectively. The real experimental scenario is more complicated, which is in between the clean surface and 0.25 ML CNBT coverage models (Supplementary Fig. 22), therefore the barrier should be in between the above two values. Assuming a reaction rate pre-exponential factor ${ }^{25}$ of $10^{13} \mathrm{~s}^{-1}$, this means that transfer of $\mathrm{H}$ atoms from $\mathrm{Pd}$ to $\mathrm{Au}$ happens within seconds at room temperature, which confirms the feasibility of the diffusion of $\mathrm{H}$ atoms from $\mathrm{Pd}$ to the neighboring $\mathrm{Au}$ area. Note that in the experiment, $\mathrm{Pd}$ areas also have a high coverage of surface $\mathrm{H}$, which can block $\mathrm{H}$ atoms that have diffused to Au from returning, thus acting as a driving force for $\mathrm{H}$ spillover.

Another striking feature of our system is that CABT was the only hydrogenation product observed, and in particular, no hydrodechlorination product was formed. The selectivity of the Pd catalysts using thiolate SAMs has been demonstrated before, for example for the selective formation of 1-epoxybutane from 1-epoxy-3-butene on $\mathrm{Pd}^{26}$. DFT calculations were conducted to obtain insight into the reason behind the reactivity and the unique chemoselectivity. The calculations suggest that the existence of adsorbed $\mathrm{H}$ atoms weakens the metal-sulfur bond (Supplementary Fig. 18, 19 and 20). We therefore surmise that a fraction of the thiol molecules desorb from the surface, resulting in a reduced surface coverage of thiolates. This is confirmed by the measurement of interfacial capacitance (Supplementary Fig. 22). With some empty 
spaces nearby (modeled in a $2 \times 4$ unit cell with 1 CNBT), a CNBT molecule can lean down on the surface bringing the $\mathrm{NO}_{2}$ group closer to the surface $\mathrm{H}$ atoms. We found a similar CNBT adsorption geometry at an even lower coverage (modeled in $4 \times 4$ cell with 1 CNBT, Supplementary Figure 24). This tilted adsorption geometry allows a HoriutiPolanyi mechanism (Fig. 6b, Supplementary Fig. 23a). Only the first step of this reaction is modeled; we expect that the following steps are similar. Transition-state calculations show that the $\mathrm{NO}_{2}$ group can pick up a $\mathrm{H}$ atom from the surface with a potential energy barrier of only $0.74 \mathrm{eV}$ (Fig. 6b). One might expect that hydrodechlorination of CNBT is a competing reaction. To consider this possibility, we started with either an oxidative addition $^{27}$ (Figure 6c) or a radical mechanism ${ }^{28}$ (Supplementary Fig. 23b) but found only unstable intermediates. Our interpretation is that the strong thiol-metal interaction limits the adsorption orientation of CNBT molecules ${ }^{29}$, resulting in a high energy difference $(1.8 \mathrm{eV})$, which explains why intermediates for the hydrodechlorination of CNBT are not formed and that the reaction is not observed in our experiments. In contrast, the possible intermediate structure for the hydrodechlorination of chloro-nitrobenzene (CNB) can be formed, which is in agreement with the previously reported experimental results $^{30}$. The energy difference for this reaction is only $0.1 \mathrm{eV}$ (Figure $6 \mathrm{~d}$ ), substantially lower than the one required for the hydrodechlorination of CNBT $(1.8 \mathrm{eV})$. These calculations agree well with our experimental results and provide a plausible explanation for the high chemoselectivity observed on $\mathrm{Pd}$ and $\mathrm{Au}$. 


\section{b}

a

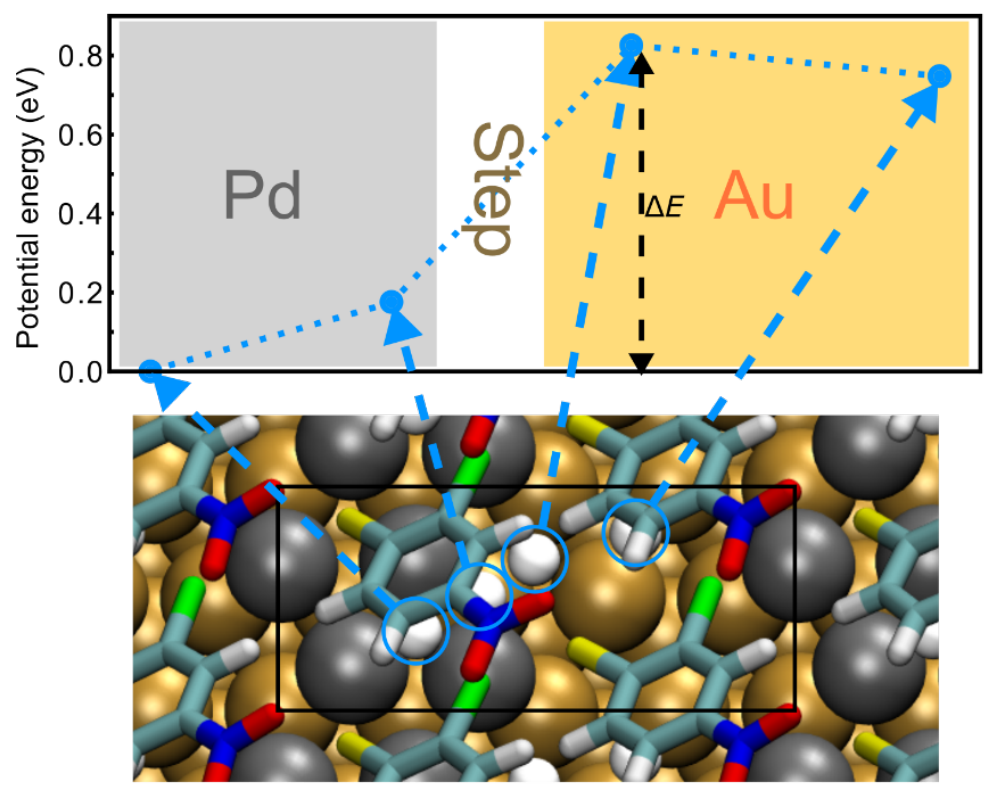

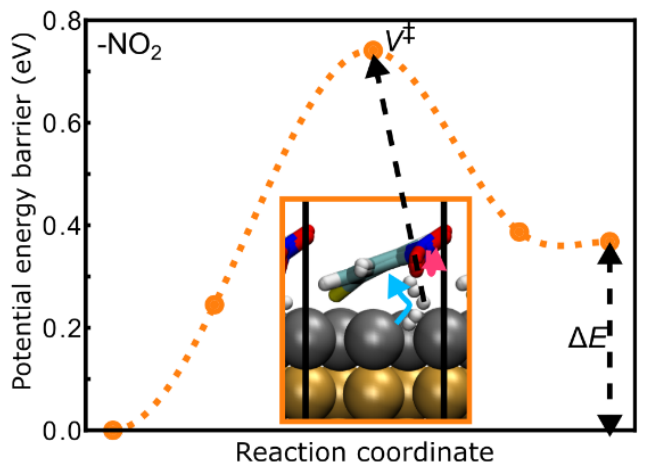

C

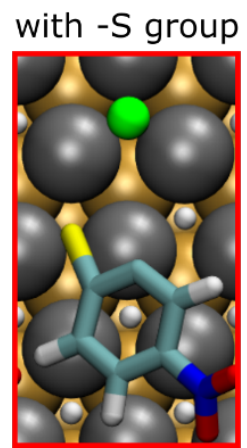

$\Delta E=1.8(\mathrm{eV})$

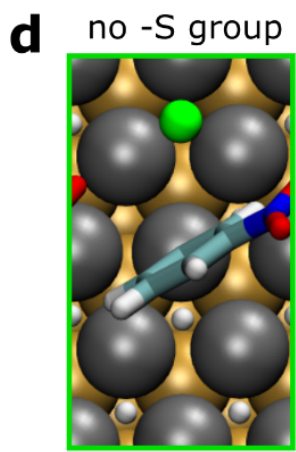

$\Delta E=0.1(\mathrm{eV})$

Figure 6. DFT calculations. a. Potential energy profile of a $\mathrm{H}$ atom moving from $\mathrm{Pd}$ to $\mathrm{Au}$ and atomic model illustration of $\mathrm{H}$ diffusion from $\mathrm{Pd}$ to $\mathrm{Au}$. This image is for illustration purposes only, i.e., the surface atoms and CNBT molecules are immobile in these calculations. A better modeling of this process is discussed in the supplementary information. b. Reaction pathway and potential energy barrier for the hydrogenation of $\mathrm{NO}_{2}$ group on $\mathrm{Pd}_{\mathrm{ML}} / \mathrm{Au}$. The inset shows the geometry of the pathway with the dashed arrow pointing to the $\mathrm{H}$ at the transition state. c-d. Possible intermediate structures and energy differences $(\Delta \mathrm{E})$ between the reactant and an intermediate state for the hydrodechlorination of CNBT (c) and of chloro-nitrobenzene (d).

In conclusion, we applied TERS imaging to investigate the hydrogenation of CNBT SAMs on $\mathrm{Pd} / \mathrm{Au}$ bimetallic catalysts under mild conditions with around $10 \mathrm{~nm}$ chemical spatial resolution. TERS 1D line scans and 2D maps were used to spectroscopically visualize the reactive sites, which revealed the relationship between surface structures and catalytic reactivity. Moreover, direct spectroscopic evidence for hydrogen spillover from $\mathrm{Pd}$ to $\mathrm{Au}$ was obtained, by correlating the distribution of the hydrogenation products with the co-localized STM image. We found that the reactive regions were 
located not only on the Pd area but also to some extent on the adjacent Au area (within 15-30 nm). The observed hydrogen spillover is in line with DFT calculations of the reaction rates. Our results improve the understanding of the spatial distribution of active hydrogen on bimetallic surfaces and highlight the importance of spillover for the reactivity. Tip-enhanced Raman spectromicroscopy, which provides chemical information with nanometer spatial resolution, is a powerful analytical technique for the investigation of interfacial catalysis at the molecular level.

\section{Methods}

STM-TERS setup. Electrochemically etched $\mathrm{Ag}_{\text {tips }}{ }^{31}$ were used to obtain both the STM images and the TER spectra. A $632.8 \mathrm{~nm}$ He-Ne laser with an intensity of $70 \mu \mathrm{W}$ was used as the excitation source. All STM-TERS measurements were performed on a top-illumination TERS setup that combines STM with a Raman spectrometer (NT-MDT, Russia, NTEGRA Spectra Upright). An air objective (100 ×, NA = 0.7, Mitutoyo, Japan) was used for both excitation and collection of the TERS signals. For all measurements, the tunneling current was $200 \mathrm{pA}$, the tunneling bias was $0.2 \mathrm{~V}$, and the acquisition time was $2 \mathrm{~s}$ per spectrum. The TERS intensities were analyzed following far-field background subtraction.

Submonolayer deposition Pd on a Au (111) substrate. Au (111) single crystal substrates were prepared by Clavilier's method ${ }^{32}$. The average diameter of an Au bead was ca. $3 \mathrm{~mm}$. A Pd submonolayer on the Au (111) substrate was fabricated using the underpotential deposition (UPD) method ${ }^{18,33}$. The UPD of Pd on the Au (111) surface was performed by linear sweep voltammetry (LSV) in an electrolyte solution consisting of $0.1 \mathrm{mM} \mathrm{H}_{2} \mathrm{PdCl}_{4}$ and $0.1 \mathrm{M} \mathrm{H}_{2} \mathrm{SO}_{4}$ with a scan rate of $2 \mathrm{mV} / \mathrm{s}$. The measurements were conducted on a SRSLab EC301 potentiostat (Stanford Research Systems, USA) with a three-electrode configuration. The $\mathrm{Au}(111)$ was used as the working electrode, a $\mathrm{Pd}$ wire was used as a quasi-reference electrode, and a Au wire was used as a counter electrode. 
Before the Au bead was flame-annealed again for reuse, the deposited Pd layer was first removed by electropolishing. The Au beads were immersed in $0.1 \mathrm{M} \mathrm{H}_{2} \mathrm{SO}_{4}$, a voltage of $6 \mathrm{~V}$ was applied for $30 \mathrm{~s}$, then it was washed with distilled water, and immersed in $0.1 \mathrm{M} \mathrm{HCl}$ for 2 minutes. This procedure was repeated twice.

Template-stripped (TS) Au substrates. TS Au substrates ${ }^{34}$ were prepared by thermally evaporating a $200 \mathrm{~nm}$ Au film onto flat Si wafers. Before Au deposition, the $\mathrm{Si}$ wafers were sonicated in ethanol for 15 minutes and then immersed in Piranha solution for 30 minutes, flushed with ultrapure water and dried with $\mathrm{N}_{2}$ prior to use. After deposition, pieces of glass were glued onto the Au surface by a glue (NOA61 UV curable glue, Thorlabs $\mathrm{GmbH}$, Germany) which can be cured by irradiation with UV light (365 nm) for 20 mins. The TS Au substrates were freshly stripped from the Si wafer before use.

Pd-coated Au substrates. Pd-coated Au substrates were prepared by evaporating 5 $\mathrm{nm} \mathrm{Pd}$ onto the surface of TS Au substrates under high vacuum $\left(1 \times 10^{-6} \mathrm{mbar}\right)$ using a physical vapor deposition setup (MED 020, BAL-TEC, Leica microsystems GmbH, Switzerland).

$\mathrm{Au}$ and Pt substrates for TPD-MS. Glass slides with a thickness of $0.1 \mathrm{~mm}$ were sonicated in ethanol for 15 minutes and dried with nitrogen prior to use. Au substrates were prepared by thermally evaporating $10 \mathrm{~nm}$ Au film onto clean glass slides. Pt substrates were prepared by thermally evaporating $1 \mathrm{~nm}$ Pt onto Au film-coated glass slides. Pt islands were expected to form on the Au film.

Metal nanoparticles for In-situ SERS measurements. $55 \mathrm{~nm}$ Au NPs were synthesized via a standard sodium citrate reduction method. ${ }^{35} 200 \mathrm{~mL}$ of chloroauric acid $(0.01$ weight $\%$ ) was boiled to reflux, and then $1.4 \mathrm{~mL}$ of sodium citrate (1 weight \%) were added to the boiling solution. The mixture was refluxed for 40 minutes, and then cooled to room temperature.Pd@AuNPs were prepared by mixing $30 \mathrm{~mL}$ of $55 \mathrm{~nm} \mathrm{Au}$ NPs with $9.97 \mathrm{~mL} \mathrm{H}_{2} \mathrm{PdCl}_{4}(1 \mathrm{mM})$ under stirring. The mixture was cooled to $4^{\circ} \mathrm{C}$ in an ice bath, and then $50 \mathrm{~mL}$ of ascorbic acid $(10 \mathrm{mM})$ were slowly added under vigorous stirring. Finally, the mixture was stirred for another 30 minutes to completely reduce $\mathrm{H}_{2} \mathrm{PdCl}_{4}$. 
Sample preparation. Metal substrates were immersed overnight in a $1 \mathrm{mM}$ solution of CNBT to allow the formation of a self-assembled monolayer on the surface. For the TERS measurement of CABT on Pd, a Pd on Au substrate was immersed in a $1 \mathrm{mM}$ solution of CABT.

In-situ SERS measurements. Droplets of AuNPs and Au@PdNPs were deposited onto clean Si wafers, respectively. The substrates were dried under vacuum. The substrates were immersed in a $1 \mathrm{mM}$ solution of CNBT for $2 \mathrm{~h}$. The substrates were cleaned with ethanol and dried with $\mathrm{N}_{2}$ prior to use. One of the substrates was put into a reaction cell sealed with a quartz plate, which allowed for the penetration of the laser. While a flow of $\mathrm{H}_{2}$ flushed into the chamber, the Raman spectra were recorded continuously with an acquisition time of $1 \mathrm{~s}$ per spectrum.

TPD-MS measurements. A plasma-based soft ionization source (active capillary plasma ionization source ${ }^{36}$ directly coupled to a high-resolution mass spectrometer (LTQ Orbitrap, Thermo Fischer Scientific, San Jose, U.S.A) was used to identify the species desorbed from the sample surface at atmospheric pressure. The active capillary plasma ionization source is based on dielectric barrier discharge ionization and consists of two electrodes that are separated by a glass capillary. A sine-modulated high voltage (2.3 kVpp, $47 \mathrm{kHz}$ ) was applied to the outer electrode, while the inner electrode was grounded. The SAM sample was heated in our custom-made temperature-programmed chamber, which was directly connected to our plasma source. A detail description of the setup can be found in the work of J. Szczerbińsky et al. ${ }^{37}$. The temperature was ramped from $23{ }^{\circ} \mathrm{C}$ to $300{ }^{\circ} \mathrm{C}$. The desorption chamber was flushed with nitrogen gas (1.3 $\mathrm{L} / \mathrm{min}$ ), which was also used as carrier and plasma discharge gas. Mass spectra were acquired in positive ion mode with a resolution of $30000(\mathrm{~m} / \mathrm{z} 400)$, over a mass range of $50-500$.

Surface coverage measurements. The measurements were carried out in $0.1 \mathrm{M}$ $\mathrm{NaClO}_{4}$ aqueous solution after deaeration within the potential window of the double layer region (no faradic reaction), which is reflected by the near rectangular shape of the cyclic voltammograms (Supplementary Figure 22). Here, we use a scan rate of $5 \mathrm{mV} / \mathrm{s}$, and the current density at $0.22 \mathrm{~V}$ is used to calculate the capacitance. 
DFT calculations. DFT calculations were carried out using the Vienna ab-initio Simulation Package $(\mathrm{VASP})^{38}$ with the optB88-vdW functional ${ }^{39}$, which accurately accounts for van-der-Waals interactions, and has been widely used to study the adsorption of molecules on metal surfaces ${ }^{40,41}$. The lattice parameters of a variety of solids predicted by the optB88-vdW functional are also in good agreement with the experimental lattice parameters ${ }^{42}$.

A plane-wave cutoff of $450 \mathrm{eV}$ was used throughout. The metal surfaces were represented using a slab with 4 layers of $\mathrm{Au}$ (and 1 layer of $\mathrm{Pd}$ on top for the $\mathrm{Pd}$ islands) in a $2 \times 2$-unit cell with a $7 \times 7 \times 1 \mathrm{~K}$-point mesh. We used larger unit cells for the investigation of hydrogenation mechanisms with an empty space, as well as for the calculation of hydrogen diffusion ( $4 \times 2$-unit cell). A vacuum of at least $14 \AA$ was placed above each surface. The climbing image nudged elastic band (Cl-NEB) method ${ }^{43}$ was used to obtain the potential energy barriers and minimal energy pathways. The bottom 3 layers of the substrate were fixed during the optimization while all the other atoms were flexible. The force convergence criteria for the geometry optimizations and $\mathrm{Cl}$ NEB calculations was $0.02 \mathrm{eV} / \AA$. All the atomic coordinates of the optimized computational models, as well as the initial and final configurations of molecular dynamics trajectories are available in Supplementary files.

\section{Data availability}

The original data used in this publication are made available in a curated data archive at ETH Zurich (https://www.researchcollection.ethz.ch) under the DOI: 10.3929/ethz-b000423837. or are available from the corresponding author upon reasonable request.

\section{Code availability}

The matlab codes used for processing the data are made available in a curated data archive at ETH Zurich (https://www.researchcollection.ethz.ch) under the DOI: 10.3929/ethz-b-000423837. or are available from the corresponding author upon reasonable request. 


\section{References}

1. Buurmans, I. L. C. \& Weckhuysen, B. M. Heterogeneities of individual catalyst particles in space and time as monitored by spectroscopy. Nat. Chem. 4, 873-886 (2012).

2. Sambur, J. B., Chen, T. Y., Choudhary, E., Chen, G., Nissen, E. J., Thomas, E. M., Zou, N. \& Chen, P. Sub-particle reaction and photocurrent mapping to optimize catalyst-modified photoanodes. Nature 530, 77-80 (2016).

3. Agarwal, N., Freakley, S. J., McVicker, R. U., Althahban, S. M., Dimitratos, N., He, Q., Morgan, D. J., Jenkins, R. L., Willock, D. J., Taylor, S. H., Kiely, C. J. \& Hutchings, G. J. Aqueous Au-Pd colloids catalyze selective $\mathrm{CH} 4$ oxidation to $\mathrm{CH} 3 \mathrm{OH}$ with $\mathrm{O} 2$ under mild conditions. Science 358, 223-227 (2017).

4. Cárdenas-Lizana, F., Gómez-Quero, S., Hugon, A., Delannoy. L, Louis, C. \& Keane, M. A. Pd-promoted selective gas phase hydrogenation of $p$-chloronitrobenzene over alumina supported Au. J. Catal. 262, 235-243 (2009).

5. Lucci, F. R., Darby, M. T., Mattera, M. F. G., Ivimey, C. J., Therrien, A. J., Michaelides, A., Stamatakis, M. \& H. Sykes, E. Charles. Controlling Hydrogen Activation, Spillover, and Desorption with Pd-Au Single-Atom Alloys. J. Phys. Chem. Lett. 7, 480-485 (2016).

6. Marcinkowski, M., Jewell, A., Stamatakis, M., Boucher, M., Lewis, E., Murphy, C., Kyriakou, G. \& Sykes, E. C. Controlling a spillover pathway with the molecular cork effect. Nat. Mater. 12, 523-528 (2013)

7. Huizinga, T. \& Prins, R. Behavior of titanium (3+) centers in the low-and hightemperature reduction of platinum/titanium dioxide, studied by ESR. J. Phys. Chem. 85, 2156-2158 (1981).

8. Briggs, N. M., Barrett, L., Wegener, E. C., Herrera, L. V., Gomez, L. A., Miller, J. T. \& Crossley, S. P. Identification of active sites on supported metal catalysts with carbon nanotube hydrogen highways. Nat. Comm. 9, 3827 (2018). 
9. Kyriakou, G., Boucher, M. B., Jewell, A. D., Lewis, E. A., Lawton, T. J., Baber, A. E., Tierney, H. L., Flytzani-Stephanopoulos, M. \& Sykes, E. Charles H. Isolated Metal Atom Geometries as a Strategy for Selective Heterogeneous Hydrogenations. Science 335, 1209-1212 (2012).

10. Miller, J. T., Meyers, B. L., Modica, F. S., Lane, G. S., Vaarkamp, M. \& Koningsberger, D. C. Hydrogen Temperature-Programmed Desorption (H2 TPD) of Supported Platinum Catalysts. J. Catal. 143, 395-408 (1993).

11. Karim, W., Spreafico, C., Kleibert, A., Gobrecht, J., VandeVondele, J., Ekinci, Y. \& van Bokhoven, J. A. Catalyst support effects on hydrogen spillover. Nature 541, 6871 (2017).

12. van Lent, R., Auras, S., Cao, K., Walsh, A., Gleeson, M. \& Juurlink, L. B. F. Sitespecific reactivity of molecules with surface defects-the case of $\mathrm{H} 2$ dissociation on Pt. Science 363, 155-157 (2019).

13. Dong, J., Zhang, X., Briega-Martos, V., Jin, X., Yang, J., Chen, S., Yang, Z., Wu, D., Feliu, J. M., Williams, C. T., Tian, Z. Q. \& Li, J. F. In situ Raman spectroscopic evidence for oxygen reduction reaction intermediates at platinum single-crystal surfaces. Nat. Energy 4, 60-67 (2019).

14. Zhong, J., Jin, X., Meng, L., Wang, X., Su, H., Yang, Z., Williams, C. T. \& Ren, B. Probing the electronic and catalytic properties of a bimetallic surface with $3 \mathrm{~nm}$ resolution. Nat. Nanotechnol. 12, 132-136 (2017).

15. Zhang, R., Zhang, Y., Dong, Z. C., Jiang , S., Zhang, C., Chen, L. G., Zhang, L., Liao, Y., Aizpurua, J., Luo, Y., Yang, J. L. \& Hou, J. G. Chemical mapping of a single molecule by plasmon-enhanced Raman scattering. Nature 498, 82-86 (2013).

16. Lee, J., Crampton, K. T., Tallarida, N. \& Apkarian, V. A. Visualizing vibrational normal modes of a single molecule with atomically confined light. Nature $568,78-$ 82 (2019).

17. van Schrojenstein Lantman, E. M., Deckert-Gaudig, T., Mank, A. J. G., Deckert, V. \& Weckhuysen, B. M. Nat. Nanotechnol.7, 583-586 (2012). 
18. Herrero, E., Buller, L. J. \& Abruña, H. D. Underpotential Deposition at Single Crystal Surfaces of Au, Pt, Ag and Other Materials. Chem. Rev. 101, 1897-1930 (2001).

19. Lin, L., Yao, S., Gao, R., Liang, X., Yu, Q., Deng, Y., Liu, J., Peng, M., Jiang, Z., Li, S., Li, Y., Wen, X., Zhou, W. \& Ma, D. A highly CO-tolerant atomically dispersed Pt catalyst for chemoselective hydrogenation. Nat. Nanotechnol. 14, 354-361 (2019).

20. Pan, M., Brush, A. J., Pozun, Z. D., Ham, H. C., Yu, W., Henkelman, G., Hwang, G. S. \& Mullins, C. B. Model studies of heterogeneous catalytic hydrogenation reactions with gold. Chem. Soc. Rev. 42, 5002-5013 (2013).

21. Chen, C., Hayazawa N. \& Kawata S. A $1.7 \mathrm{~nm}$ resolution chemical analysis of carbon nanotubes by tip-enhanced Raman imaging in the ambient. Nat. Commun. $\mathbf{5}$, $3312(2014)$.

22. Su, H., Feng, H., Zhao, Q., Zhang, X., Sun, J., He, Y., Huang, S., Huang, T., Zhong, J., Wu, D. \& Ren, B. Probing the Local Generation and Diffusion of Active Oxygen Species on a Pd/Au Bimetallic Surface by Tip-Enhanced Raman Spectroscopy. J. Am. Chem. Soc. 142, 1341-1347 (2020).

23. Lopez, N., Łodziana, Z., Illas, F. \& Salmeron, M. When Langmuir Is Too Simple: H2 Dissociation on Pd(111) at High Coverage. Phys. Rev. Lett. 93, 146103 (2004).

24. Groß, A. \& Dianat, A. Hydrogen Dissociation Dynamics on Precovered Pd Surfaces: Langmuir is Still Right. Phys. Rev. Lett. 98, 206107 (2007).

25. Lauhon, L. J. \& Ho, W. Direct Observation of the Quantum Tunneling of Single Hydrogen Atoms with a Scanning Tunneling Microscope. Phys. Rev. Lett. 89, 079901 (2002).

26. Marshall, S., O’Brien, M., Oetter, B., Corpuz, A., Richards, R. M., Schwartz, D. K. \& Medlin, J. W. Controlled selectivity for palladium catalysts using self-assembled monolayers. Nat. Mater. 9, 853-858 (2010).

27. Abazari, R., Heshmatpour, F. \& Balalaie, S. Pt/Pd/Fe Trimetallic Nanoparticle Produced via Reverse Micelle Technique: Synthesis, Characterization, and Its Use 
as an Efficient Catalyst for Reductive Hydrodehalogenation of Aryl and Aliphatic Halides under Mild Conditions. ACS Catal. 3, 139-149 (2013).

28. de Pedro, Z. M., Casas, J. A., Gomez-Sainero, L. M. \& Rodriguez, J. J. Hydrodechlorination of dichloromethane with a $\mathrm{Pd} / \mathrm{AC}$ catalyst: Reaction pathway and kinetics. Appl. Catal. B 98, 79-85 (2010).

29. Qian, X., Emory, S. R. \& Nie, S. Anchoring Molecular Chromophores to Colloidal Gold Nanocrystals: Surface-Enhanced Raman Evidence for Strong Electronic Coupling and Irreversible Structural Locking. J. Am. Chem. Soc. 134, 2000-2003 (2012).

30. Coq, B., Ferrat, G. \& Figueras, F. Conversion of chlorobenzene over palladium and rhodium catalysts of widely varying dispersion. J. Catal. 101, 434-445 (1986).

31. Stadler, J., Schmid, T. \& Zenobi, R. Nanoscale chemical imaging using topillumination tip-enhanced Raman spectroscopy. Nano Lett. 10, 4514-4520 (2010).

32. Clavilier, J., Faure, R., Guinet, G. \& Durand, R. Preparation of monocrystalline Pt microelectrodes and electrochemical study of the plane surfaces cut in the direction of the $\{111\}$ and $\{110\}$ planes. J. Electroanal. Chem. 107, 205-209 (1979).

33. Kibler, L. A., Kleinert, M., Randler, R. \& Kolb, D. M. Initial stages of Pd deposition on Au (hkl) Part I: Pd on Au (111). Surf. Sci. 443, 19-30 (1999).

34. Weiss, E. A., Kaufman, G. K., Kriebel, J. K., Li, Z., Schalek, R. \& Whitesides, G. M. $\mathrm{Si} / \mathrm{SiO}_{2}$-templated formation of ultrafast metal surfaces on glass, polymer, and solder supports: Their use as substrates for self-assembled monolayers. Langmuir 23, 9686-9694 (2007).

35. Zhang, Y.-J., Li, S.-B., Duan, S., Lu, B.-A., Yang, J., Panneerselvam, R., Li, C.-Y., Fang, P.-P., Zhou, Z.-Z., Phillips, D. L., Li J.-F. \& Tian Z.-Q. Probing the electronic structure of heterogeneous metal interfaces by transition metal shelled gold nanoparticle-enhanced Raman spectroscopy. J. Phys. Chem. C 120, 20684-20691 (2016). 
36. Gyr, L., Klute, F. D., Franzke, J., \& Zenobi, R. Characterization of a nitrogen-based dielectric barrier discharge lonization source for mass spectrometry reveals factors important for soft ionization. Anal. Chem. 91, 6865-6871 (2019).

37. Szczerbiński, J., Gyr, L., Kaeslin, J. \& Zenobi, R. Plasmon-driven photocatalysis leads to products known from E-beam and X-ray-induced surface chemistry. Nano Lett. 18, 6740-6749 (2018).

38. Kresse, G. \& Furthmüller, J. Efficient iterative schemes for ab initio total-energy calculations using a plane-wave basis set. Phys. Rev. B 54, 11169 (1996).

39. Klimeš, J., Bowler, D. R. \& Michaelides, A. Chemical accuracy for the van der Waals density functional. J. Phys. Condens. Matter 22, 022201 (2010).

40. Carrasco, J., Klimeš, J. \& Michaelides, A. The role of van der Waals forces in water adsorption on metals. J. Chem. Phys. 138, 024708 (2013).

41. Berland, K., Cooper, V. R., Lee, K., Schröder, E., Thonhauser, T., Hyldgaard, P. \& Lundqvist, B. I. van der Waals forces in density functional theory: a review of the vdW-DF method. Rep. Prog. Phys. 78, 066501 (2015).

42. Klimeš, J., Bowler, D. R. \& Michaelides, A. Van der Waals density functionals applied to solids. Phys. Rev. B 83, 195131 (2011).

43. Henkelman, G., Uberuaga, B. P. \& Jónsson, H. A climbing image nudged elastic band method for finding saddle points and minimum energy paths. J. Chem. Phys. 113, 9901 (2000).

\section{Contributions}

R. Z. and J.-F. L. supervised the project. L.-Q. Z. conceived of the ideas. L.-Q. Z. and H. Y. designed the experiments. H. Y., L.-Q. Z. and N. P. performed the experiments. W. F. and J. O. R. performed the DFT calculations. Y.-H. L. and L.-Q. Z. performed TPD-MS experiments. G. G., H.-S. S. and B. R. contributed to electrochemistry. H. Y., L.-Q. Z., and W. F. wrote the manuscript with the help of G. G. and H. Z. All authors discussed the results and commented on the manuscript. 


\section{Competing interests}

The authors declare no competing interests.

\section{Additional information}

Supplementary information is available for this paper, including supplementary figures, tables and discussions.

\section{Acknowledgements}

This work was supported financially by the European Research Council (ERC) program (grant \# 741431 - 2DNanoSpec), the Natural Science Foundation of China (NSFC) (grants \# 21925404, 21775127, and 21703181), the Fundamental Research Funds for the Central Universities (20720190044) and MOST (2019YFA0705402). L.-Q. Z. was financially supported by the Chinese Scholarship Council for a Ph.D. student fellowship. H. Y. was financially supported by the Sino-Swiss Science and Technology Cooperation program (grant \# EG22-122016). W. F. and J. O. R. are supported by the Swiss National Science Foundation (project \# 175696.) The authors also acknowledge Dr. Antonella Rossi (ETH Zurich) and Giovanni Cossu (ETH Zurich) for help with the XPS measurements. DFT computations were supported by the High-Performance Computing Team at ETH Zurich. H. Y. and L.-Q. Z. also thank Alina Begley, Jonas Bastian Metternich, Dr. Jacek Szczerbińsky and Prof. Jeroen A van Bokhoven (all from ETH Zurich) for insightful discussions. H. Y. thanks Wei-Qiong Li (Xiamen University) for the coverage measurement. 